\title{
Modified Chopart's Amputation; Is It an Alternative to Below Knee Amputation?
}

\author{
Amro M.Elboushi, ${ }^{1}$ MD; Waleed A. Sorour, ${ }^{1}$ MD; Medhat E. El-Leboudy, ${ }^{1}$ MD; \\ Amr M. Eladawy, ${ }^{2}$ MD.
}

1) Vascular Surgery Unit, Faculty of Medicine, Zagazig University. 2) Orthopedic Department, Faculty of Medicine, Zagazig University.

Aims: To evaluate short term results of both modified Chopart's amputation \& below knee amputation in the management of unsalvageable forefoot in diabetic patients.

Settings and design: Prospective non-randomized study.

Patients and methods: This study was conducted at the vascular surgery unit, Zagazig university hospital between December 2011 and December 2014. The patients were divided into two groups. The $1^{\text {st }}$ group included 19 patients who underwent below knee amputation (BKA). The $2^{\text {nd }}$ group included 15 patients who underwent modified Chopart's amputation. Two cases in the first group were excluded because they were missed during follow-up period; the remaining 17 cases included 13 cases of infection and 4 cases of ischemia in the first group while there were 12 cases of infection and 3 cases of ischemia in the second group. The Arabic version of the RAND-36 Survey from the RAND Medical Outcomes Study was used at 12 months postoperatively.

Results: In the $1^{\text {st }}$ group who underwent BKA, 2 patients were excluded from the study because they were missed during follow-up, the remaining 17 patients completed the study; they were 10 males and 7 females with a mean age of $51.2 \pm 10.5$ years. The 2 nd group included 15 patients who underwent modified Chopart's amputation; they were 9 males and 6 females with a mean age of $47.9 \pm 11.05$ years. The demographic data were not statistically significant between the two groups. The mean follow up of the patients in both groups was for $17.3 \pm 1.9$ months. Six month walking distance and rehabilitation time were significant between the two groups. The RAND 36 questionnaires in this study showed significant difference between the modified Chopart's and BKA group in the physical function, emotional role limitation and social function, but the two groups were comparable in the other items.

Conclusion: Modified Chopart's amputation showed better physical function, emotional role limitation and social function according to the RAND 36 questionnaires in the management of unsalvageable forefoot in selected patients but it isn't a replacement for higher amputations like BKA. Future long term follow up studies with larger sample sizes is needed to further evaluate this technique.

Key words: Modified Chopart, diabetic foot and quality of life.

\section{Introduction:}

Amputation has a significant effect on the patients' quality of life, mobility, social activities and psychological status. ${ }^{1}$ Taking the decision of amputation isn't as easy as it seems. Rapid decisions may end in loss of viable tissue and increase in the weight per square centimeter making the remaining stump more susceptible to breakdown. Following an algorithm for foot amputations like the one utilized at the Georgetown Limb Center aims to maximize foot length and optimize foot biomechanics so that subsequent breakdown does not occur. Principles of such algorithm are controlling systemic infection followed by insuring adequate blood supply 
and insuring eradication of local infection and the last and most important factor is creating a biomechanical stable amputation stump. ${ }^{2}$

Francois Chopart first described disarticulation at the midtarsal joint in 1792. Chopart's amputation is amputation of all tissue distal to talonavicular and calcaneocuboid joints. ${ }^{3}$ Chopart's amputation since that has been differently appreciated by surgeons from inconvenient to a good option. This wide difference is due to the equinovarus deformity. ${ }^{4}$ Modifications of this amputation like tenotomy or lengthening of tendon Achilles, tendon transfer of the tibialis anterior tendon to the anterolateral aspect of the talus and arthrodesis of both ankle and subtalar joints has led to better clinical result. This encouraged surgeons to perform modified Chopart's amputation in patients with unsalvageable forefoot with intact hind foot instead of more proximal major amputation. ${ }^{3}$

Lower Limb amputation has both physiological and psychological persistent effect on a person's health related quality of life (HRQoL) which is used more frequently for outcome assessment. Walking distance after lower limb amputation is a major factor affecting independence. Independence itself is assumed to have a positive impact on HRQol regarding social and psychological wellbeing. ${ }^{5}$ A patient with lower limb amputation ability to walk is affected by the level of amputation. The higher the level of amputation the higher the energy required to walk. ${ }^{6}$ As elderly population has a higher incidence of lower limb amputation due to peripheral vascular disease and/or diabetes, the co-morbidities in this population makes walking a more challenging task. ${ }^{7}$

\section{Patients and methods:}

This is a single center, non-randomized prospective study in which we evaluated short term results of both modified Chopart's amputation and below knee amputation (BKA) in management of unsalvageable forefoot in diabetic patients. This study was conducted in vascular surgery unit, Zagazig university hospital between December 2011 and December 2014. The patients were divided into two groups; the $1^{\text {st }}$ group included 19 patients who underwent below knee amputation, and the $2^{\text {nd }}$ group included 15 patients who underwent modified Chopart's amputation.

Inclusion criteria for this study were diabetic patients with unsalvageable forefoot undergoing lower limb amputation either below knee amputation or modified Chopart's amputation; due to vascular disease or infection. Exclusion criteria were people who need higher level amputation, Patients who were mentally unable to use questionnaires, patients who were initially unable to walk due to previous disease, trauma or injury and patients with unsalvageable hind foot. Patients with insufficient plantar flab were directed to the first group (BKA).

All patients were consented for the study and its aim was thoroughly explained to them. The mean follow up of all patients in both groups was for $17.3 \pm 1.9$ months. The Arabic version of the RAND-36 Survey from the RAND Medical Outcomes Study was used at 12 months postoperatively. RAND-36 is a set of generic, coherent, and easily administered quality-of-life measures. These measures are now widely utilized by managed care organizations for routine monitoring and assessment of care outcomes in adult patients. The questionnaire addresses 9 domains that contribute to HRQoL: Physical function, role limitation physical, social function, role limitation emotional, mental health, pain, vitality, general health, and perceived change in health. Scores range from 0 (worst reported health) to 100 (best reported health). ${ }^{8}$

In this study, 2 cases in the first group were excluded because they were missed during follow-up period; the remaining 17 cases included 13 cases of infection and 4 cases of ischemia in the first group while there were 12 cases of infection and 3 cases of ischemia in the second group.

In presence of infection, surgical technique was staged in both groups; $1^{\text {st }}$ stage is drainage and debridement of gangrenous tissues with appropriate antibiotic coverage 

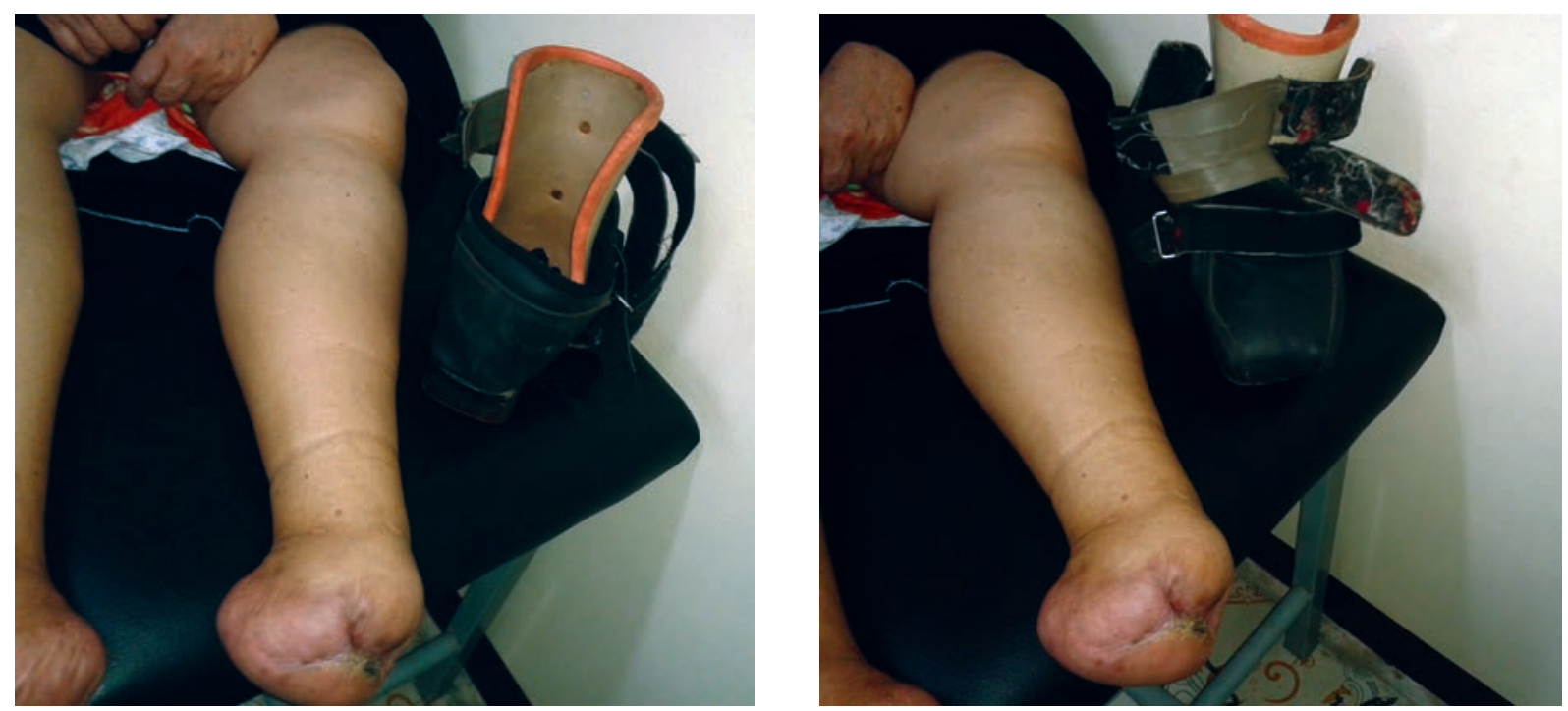

Figure (1): Fifty three years old female operated by modified Chopart's amputation with her prosthesis and diabetic shoes.

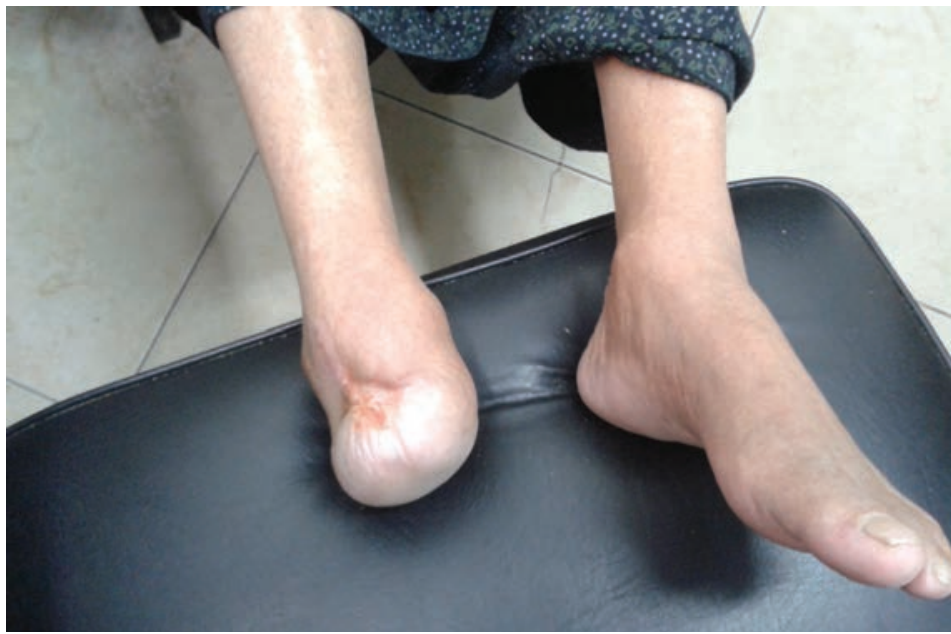

Figure (2): Sixty seven years old female operated by modified Chopart's amputation.

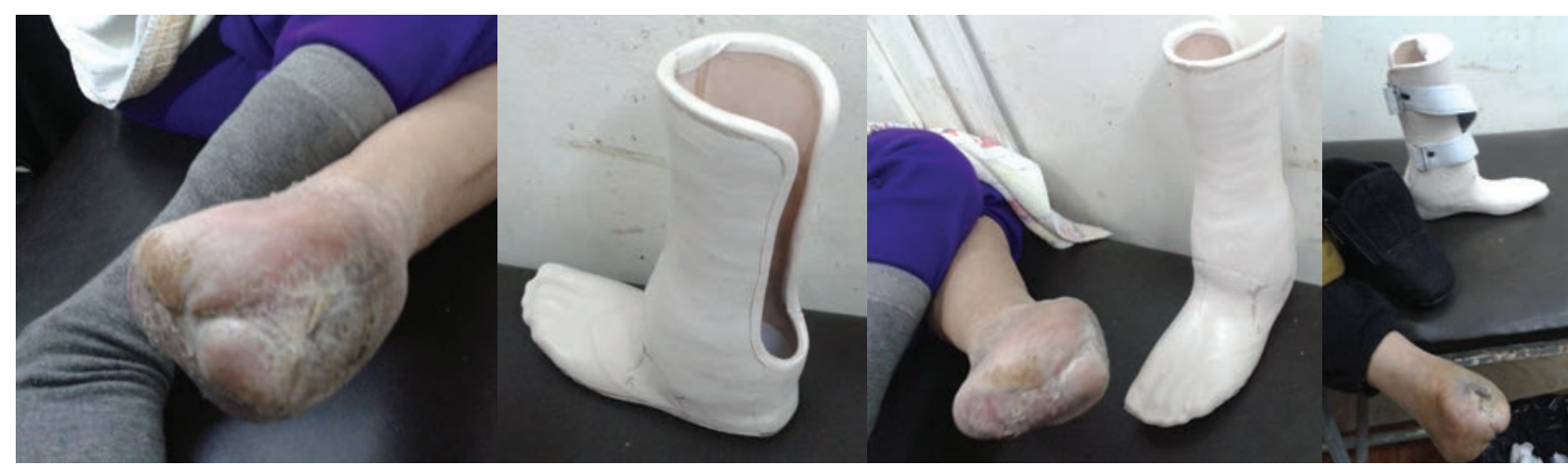

Figure (3): Fifty seven years old female patient operated by modified Chopart's amputation with her prosthesis and diabetic shoes.

guided by culture results. In presence of ischemia, vascular intervention was done before amputation (one case was managed by endovascular technique, one case underwent delayed embolectomy and the other 2 cases underwent femoropopliteal bypass in the first group, while in the second group, 2 cases were managed by endovascular technique and one case underwent aortobifemoral bypass).

Second stage was below knee amputation 

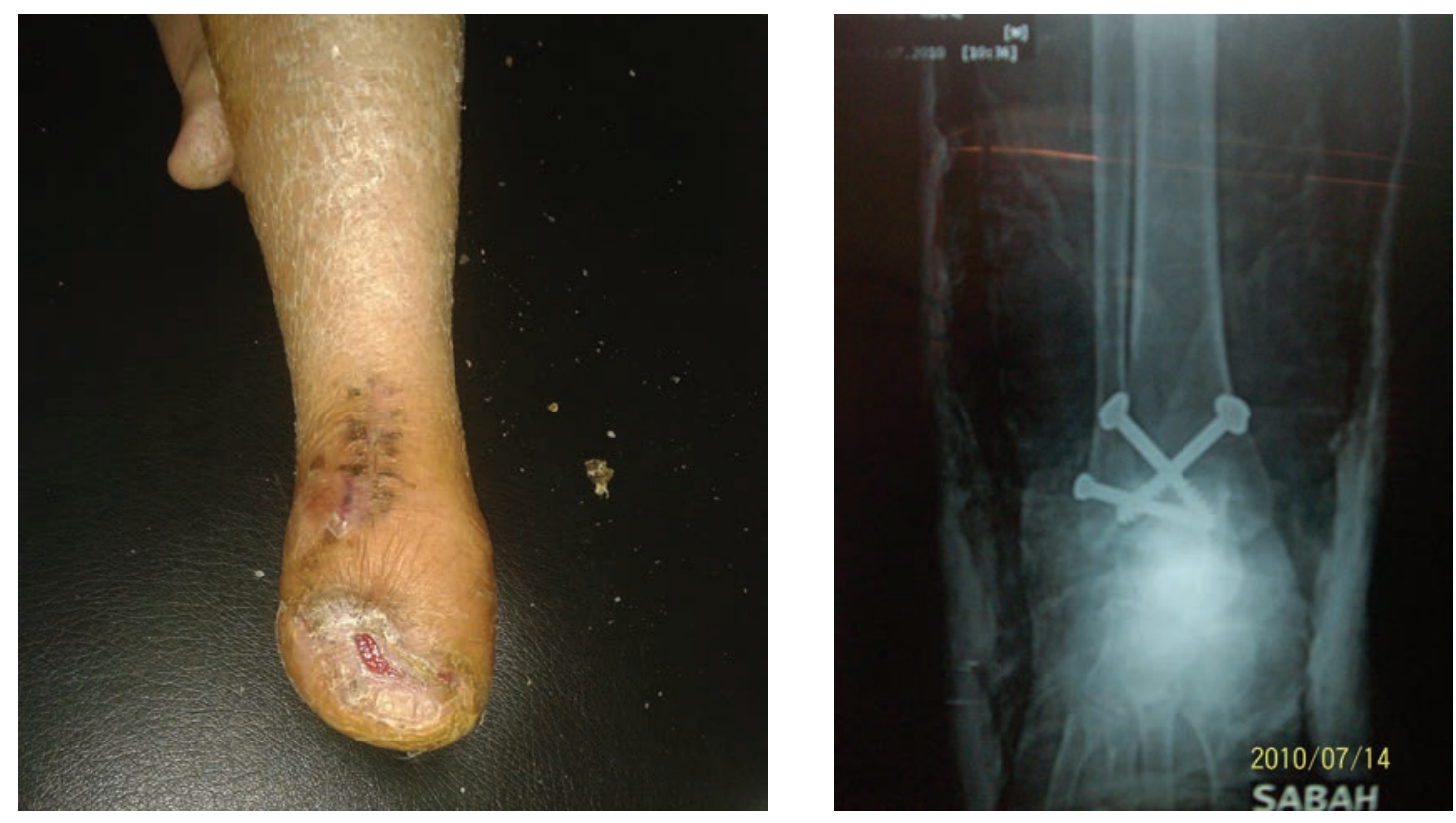

Figure (4): Forty nine years old female operated by modified Chopart's amputation; complicated by equinovarus deformity and plantar ulcer and managed by ankle arthrodesis with AP X-ray one month after arthrodesis.

Table (1): Demographic \& clinical data.

\begin{tabular}{|c|c|c|c|c|c|c|}
\hline & \multicolumn{2}{|c|}{$\begin{array}{c}\text { Group I (BKA) } \\
(\mathrm{n}=17)\end{array}$} & \multicolumn{2}{|c|}{$\begin{array}{c}\text { Group II (Modified } \\
\text { Chopart's amputation }(n=15)\end{array}$} & Test & $\mathbf{P}$ \\
\hline Age (years) & \multicolumn{2}{|c|}{$51.2 \pm 10.5$} & \multicolumn{2}{|c|}{$47.9 \pm 11.05$} & $0.866 t$ & 0.393 \\
\hline \multicolumn{7}{|l|}{ Sex } \\
\hline Male & 10 & $58.8 \%$ & 9 & $60 \%$ & \multirow{2}{*}{$0.085 \S$} & \multirow{2}{*}{0.769} \\
\hline Female & 7 & $41.2 \%$ & 6 & $40 \%$ & & \\
\hline \multicolumn{7}{|l|}{ Ischemia } \\
\hline No & 13 & $76.5 \%$ & 12 & $80 \%$ & \multirow{2}{*}{$0.035 \S$} & \multirow{2}{*}{0.851} \\
\hline Yes & 4 & $23.5 \%$ & 3 & $20 \%$ & & \\
\hline \multicolumn{7}{|l|}{ Infection } \\
\hline No & 4 & $23.5 \%$ & 3 & $20 \%$ & \multirow{2}{*}{$0.035 \S$} & \multirow{2}{*}{0.851} \\
\hline Yes & 13 & $76.5 \%$ & 12 & $80 \%$ & & \\
\hline
\end{tabular}

Quantitative data are expressed as mean \pm SD, Qualitative data are expressed as number \& percent $(\%)$; $\$$ independent samples Student-t test; $\S$ chi-square test; $p<0.05$ is significant.

in the $1^{\text {st }}$ group and modified Chopart's amputation in the second group (a long plantar flap and shorter dorsal flap were dissected from the skeleton of the foot, then exposing the midtarsal joints for disarticulation through talonavicular and calcaneocuboid joints) with transfer of the tibialis anterior tendon to the anterolateral aspect of the talus through a drill hole and tenotomy of the tendon Achilles with the application of a posterior slab for 4 weeks. During follow up, ankle arthrodesis in a slightly dorsiflexed position was done in two patients who developed an equinovarus deformity with plantar ulcer. An anterolateral incision over the ankle joint was done which allowed the curettage of the articular surfaces of the ankle joint, the ankle was held in a slightly dorsiflexed position while fixing the tibia to the talus with crossing cancellous screws, and a posterior slab was applied for 
Table (2): Rehabilitation time (weeks) \& Walking distance at 6 month.

\begin{tabular}{|c|c|c|c|c|c|c|}
\hline & \multicolumn{2}{|c|}{$\begin{array}{c}\text { Group I } \\
\text { (BKA) }(n=17)\end{array}$} & \multicolumn{2}{|c|}{$\begin{array}{c}\text { Group II (Modified } \\
\text { Chopart's amputation }(n=15)\end{array}$} & Test & $\mathbf{P}$ \\
\hline Rehabilitation time (weeks) & \multicolumn{2}{|c|}{\begin{tabular}{|l|}
$12.2 \pm 4.5$ \\
\end{tabular}} & \multicolumn{2}{|c|}{$8.9 \pm 4$} & $2.180 \%$ & 0.037 \\
\hline \multicolumn{5}{|c|}{ Walking distance at 6 month } & & \\
\hline$<100 \mathrm{~m}$ & 12 & $70.6 \%$ & 4 & $26.7 \%$ & \multirow[t]{3}{*}{$6.200 \S$} & \multirow[t]{3}{*}{0.012} \\
\hline $100-500 \mathrm{~m}$ & 4 & $23.6 \%$ & 7 & $46.6 \%$ & & \\
\hline$>500 \mathrm{~m}$ & 1 & $5.8 \%$ & 4 & $26.7 \%$ & & \\
\hline
\end{tabular}

Quantitative data are expressed as mean \pm SD, Qualitative data are expressed as number $\&$ percent $(\%)$; $\ddagger$ independent samples Student t-test; $\S$ chi-square test for trend; $p<0.05$ is significant.

Table (3): RAND-36 Questionnaire results of the 2 groups.

\begin{tabular}{|l|l|l|l|c|}
\hline & \multicolumn{1}{|c|}{$\begin{array}{c}\text { Group I } \\
\text { (BKA) (n=17) }\end{array}$} & $\begin{array}{c}\text { Group II (Modified Chopart's } \\
\text { amputation) (n=15) }\end{array}$ & Test & P \\
\hline Physical function & $60 \pm 13$ & $70 \pm 14$ & $-2.095 \ddagger$ & 0.044 \\
\hline $\begin{array}{l}\text { Role limitation due to } \\
\text { physical health }\end{array}$ & $65 \pm 25$ & $70 \pm 21$ & $-0.608 \ddagger$ & 0.547 \\
\hline $\begin{array}{l}\text { Role limitation due to } \\
\text { emotional problems }\end{array}$ & $61 \pm 15$ & $73 \pm 16$ & $-2.189 \ddagger$ & 0.036 \\
\hline Social function & $61 \pm 10$ & $69 \pm 12$ & $-2.057 \ddagger$ & 0.048 \\
\hline Mental health & $69 \pm 11$ & $76 \pm 12$ & $-1.722 \ddagger$ & 0.095 \\
\hline Pain & $62 \pm 16$ & $68 \pm 17$ & $-1.028 \ddagger$ & 0.312 \\
\hline Vitality & $72 \pm 15$ & $70 \pm 16$ & $0.365 \ddagger$ & 0.717 \\
\hline General health & $68 \pm 17$ & $73 \pm 17$ & $-0.830 \ddagger$ & 0.412 \\
\hline $\begin{array}{l}\text { Perceived change in } \\
\text { health }\end{array}$ & $62 \pm 14$ & $65 \pm 16$ & $-0.566 \ddagger$ & 0.575 \\
\hline
\end{tabular}

Quantitative data are expressed as mean $\pm \mathrm{SD} ;+$ independent samples Student- $t$ test; $p<0.05$ is significant.

Table (4): Complications.

\begin{tabular}{|c|c|c|c|c|c|c|}
\hline & \multicolumn{2}{|c|}{$\begin{array}{c}\text { Group I } \\
(\text { BKA) }(n=17)\end{array}$} & \multicolumn{2}{|c|}{$\begin{array}{c}\text { Group II (Modified Chopart's } \\
\text { amputation) }(n=15)\end{array}$} & Test & $\mathbf{P}$ \\
\hline No & 13 & $76.5 \%$ & 10 & $66.6 \%$ & \multirow{2}{*}{$0.049 \S$} & \multirow{2}{*}{0.824} \\
\hline Yes & 4 & $23.5 \%$ & 5 & $33.4 \%$ & & \\
\hline Seroma & 3 & $17.7 \%$ & 0 & $0 \%$ & \multirow{5}{*}{$9.000 \S$} & \multirow{5}{*}{0.061} \\
\hline Skin maceration & 0 & $0 \%$ & 1 & $6.7 \%$ & & \\
\hline Superficial infection & 0 & $0 \%$ & 1 & $6.7 \%$ & & \\
\hline Stump infection & 1 & $5.8 \%$ & 0 & $0 \%$ & & \\
\hline Ulcer & 0 & $0 \%$ & 3 & $20 \%$ & & \\
\hline
\end{tabular}

Qualitative data are expressed as number \& percent ( $\%) ; \S$ chi-square test; $p<0.05$ is significant. 
8 weeks.

In the BKA group, after complete healing of the wound and subsidence of stump edema using intermittent application of crepe bandages, prosthesis was designed and weight bearing was allowed (8-12 weeks). In the modified chopart's group we kept patients non weight bearing for 6 weeks followed by partial weight bearing for 2-4 weeks. After which if healing was established full weight bearing using prosthesis was started. Weight bearing for the two patients who underwent arthrodesis was postponed till union of the arthrodesis occurred (3 months).

All terms and conditions stated in RAND36 were followed and the scoring instructions provided on the website were followed. Patients who were not able to read due to vision impairment or illiteracy were helped to complete the survey. Questionnaires were completed 12 months postoperatively. Any complications, any further interference and rehabilitation time were also documented.

\section{Results:}

\section{Statistical Analysis:}

All data were collected, tabulated and statistically analyzed using SPSS 22.0 for windows (SPSS Inc., Chicago, IL, USA) \& MedCalc 13 for windows (MedCalc Software bvba). Continuous quantitative data were checked for normality by using Shapiro-Wilk test. Quantitative variables were expressed as means \pm SD. Independent samples Student t-test was used to compare between two groups of independent normally distributed data. Percent of categorical variables were compared using the Pearson's Chi-square $\left(\chi^{2}\right)$ test, also trend of change in distribution of relative frequencies between ordinal data were compared using Chi-square $\left(\chi^{2}\right)$ test for trend. All tests were two sided with $\mathrm{p}<0.05$ was considered statistically significant.

Among the patients of the 1st group who underwent BKA, 2 patients were excluded from the study because they were missed during follow-up and the remaining 17 patients completed the study, they were 10 males and 7 females with a mean age of
$51.2 \pm 10.5$ years. The 2 nd group included 15 patients who underwent modified Chopart's amputation; they were 9 males and 6 females with a mean age of $47.9 \pm 11.05$ years. The mean follow up of all patients in both groups was for $17.3 \pm 1.9$ months.

The demographic and clinical data were not statistically significant between the two groups Table (1). Six month walking distance and rehabilitation time were significant between the two groups Table (2).

The RAND 36 questionnaires in this study showed significant difference between the modified chopart's and BKA group in the physical function, emotional role limitation and social function, but the two groups were comparable in the other items Table (3).

Complications in the first group were seroma in 3 cases (which were managed by proper elevation, diuretics, antiphlogestics and removal of few sutures in two cases) and one case of stump infection (which was managed by removal of sutures and debridement of infected tissues and frequent dressings followed by secondary sutures). Complications in the modified Chopart's amputation group were one case of skin maceration, one case of superficial wound infection (which resolved after drainage of collection and a course of appropriate antibiotics) and 3 cases of ulceration. The three cases of ulcers were managed according to the cause of ulcers. Weight bearing without prosthesis was the cause in one case which was managed by minor debridement, offloading followed by using prosthesis and patient education to avoid bare stump weight bearing. The other 2 cases were due to a beginning equinovarus deformity managed by revision of stump with arthrodesis in slightly more than neutral dorsiflexion of the ankle joint. This maintains the scar away from the weight bearing area Table (4).

\section{Discussion:}

Making a decision of amputation in unsalvageable forefoot patients may be tricky. A lot of factors are involved in the decision; vascularity, presence of infection and its level, availability of enough tissue for coverage, 
patient's age, general health, life expectancy, other co-morbidities and the patients' choice and emotional wellbeing. ${ }^{9}$

Complex cases involving unsalvageable forefoot make some surgeons choose the safest operation with the highest success rate neglecting the energy expenditure leading to smaller healthy residual stump in patients who can't mobilize. ${ }^{10}$ Moreover HRQoL is a critical indicator of overall patient health; and using The RAND 36 questionnaires in this study showed significant difference between the modified Chopart's and BKA group in the physical function, emotional role limitation and social function. This agrees with the studies which established that preserving limb length has a positive impact on physical independence, self-esteem, body image perception and psychological status of the patient. ${ }^{11-13}$

Learning to walk using prosthesis requires perseverance and hard work from the patient taking in mind associated co-morbidities that make it more ponderous and tiresome. ${ }^{5}$

Six month walking distance and rehabilitation time were significant between the two groups as walking using prosthesis for modified Chopart's amputation proves to be easier requiring less effort and rehabilitation, which we think is related to preserving longer stumps with functioning joints (excluding cases needing arthrodesis), less energy expenditure, better physical, social function, and less emotional role limitation. It has been established in numerous studies that energy expenditure increases the higher the amputation level and the less number of joints. ${ }^{12-16}$ It is a logical conclusion we share with DeGere and collegues that the more distal the level of amputation the better functional outcome for the patient. ${ }^{4}$

There were 3 cases of ulceration in the modified Chopart's amputation group; they were managed according to the cause of ulcers. Weight bearing without prosthesis were the main cause in one case (which was managed by minor debridement, off-loading followed by using prosthesis and patient education to avoid bare stump weight bearing). The other 2 cases were due to a beginning equinovarus deformity managed by revision of stump with arthrodesis in slightly more than neutral dorsiflexion of the ankle joint. This maintains the scar away from the weight bearing area.

We Agree with Krause and colleagues that arthrodesis is to be used only to provide wound closure without tension as the dissection may delay wound healing and increase risk of wound infection especially in diabetic patients. Unlike Krause and colleagues we only included patients that had wounds that can only be closed primary while patients considered for free flap coverage were excluded from this study. ${ }^{9} \mathrm{We}$ used arthrodesis in 2 cases of plantar ulcers complicating equinovarus deformity.

Schade and colleagues in 2010 published a systematic review on the factors associated with successful modified Choparts amputation in diabetic patients which concluded that a functioning stump with adequate high profile prosthetic device can be maintained for $>12$ months. They also reported complications; mainly ulcers due to improper devices and unprotected ambulation which was managed with minor procedures. ${ }^{10}$

This study has a small sample size and is non-randomized but this is defensible as the right criteria have to be present so that modified Chopart's amputation can be a realistic option.

\section{Conclusion:}

Modified Chopart's amputation showed better physical function, emotional role limitation and social function according to the RAND 36 questionnaires in management of unsalvageable forefoot but it isn't a replacement for higher amputations like BKA. Future Long term follow up studies with larger sample sizes are needed to further evaluate this technique.

\section{Reference:}

1- Jordan RW, Marks A, Higman D: The cost of major lower limb amputation: A 12-year experience. Prosthet Orthot Int 2012; 36: 430 originally published online 22 March 2012. DOI: $10.1177 / 0309364612441489$

2- Attinger C, Venturi M, Kim K, Ribiero $\mathrm{C}$ : Maximizing length and optimizing 
biomechanics in foot amputations by avoiding cookbook recipes for amputation. Seminars in Vascular Surgery 2003; 16(1) : 44-66. Doi: LO.1053/svas.2003.50006

3- Yoho RM, Wilson PK, Gerres JA, Freschi S: Chopart's amputation: A 10-year case study. The Journal of Foot \& Ankle Surgery 2008; 47(4): 326-331

4- DeGere MW, Grady JF: A modification of Chopart's amputation with ankle and subtalar arthrodesis by using an intramedullary nail. The Journal of Foot \& Ankle Surgery 2005; 44(4): 281-286.

5- Fortington LV, Dijkstra PU, Bosmans JC, Post WJ, Geertzen JHB: Change in healthrelated quality of life in the first 18 months after lower limb amputation: A prospective, longitudinal study. J Rehabil Med 2013; 45: 587-594.

6- Chin T, Sawamura S, Shiba R, Oyabu H, Nagakura Y, Nakagawa A: Energy expenditure during walking in amputees after disarticulation of the hip A microprocessorcontrolled swing-phase control knee versus a mechanical-controlled stance-phase control knee. J Bone Joint Surg Br 2005; 87-B(1) 117 119. Doi: 10.1302/0301-620X.87B1.14617.

7- Ephraim PL, Dillingham TR, Sector M, Pezzin LE, Mackenzie EJ: Epidemiology of limb loss and congenital limb deficiency: A review of the literature. Arch Phys Med Rehabil 2003; 84: 747-761.

8- Anon. www.rand.org [online] available from: www.rand.org on the World WideWeb.URL:Http://www.rand.org/health/ surveys tools $/ \mathrm{mos} / \mathrm{mos}$ core 36 item.html [asccessed 2nd Nov.2011].

9- Krause F, Pfander MG, Henning J, Shafighi M, Martin Weber M: Ankle dorsiflexion arthrodesis to salvage Chopart's amputation with anterior skin insufficiency. Foot \& Ankle International 2013; 34(11) 1560-1568.

10- Schade VL, Roukis TS, Yan JL: Factors associated with successful Chopart amputation in patients with diabetes: A systematic review. Foot Ankle Spec 2010; 3: 278 DOI: 10.1177/1938640010379635

11- Baima J, Trovato M, Hopkins M, deLateur B: Achieving functional ambulation in a patient with Chopart amputation. Am J Phys Med Rehabil 2008; 87: 510-513.

12- Waters R, Perry J, Antonelli D, Hislop H: Energy cost of walking of amputees: The influence of level of amputation. J Bone Joint Surg 1976; 58A: 42-46.

13- Ward KH, Meyers MC: Exercise performance of lower-extremity amputees. Sports Med 1995; 20: 207-214, .

14- Pinzur M, Gold J, Schwartz D, Gross N: Energy demands for walking in dysvascular amputees as related to the level of amputation. Orthopedics 1992; 15: 1033-1037.

15- Peters E, Childs MR, Wunderlich RP, Harkless LB, Armstrong DG, Lavery LA: Functional status of persons with diabetes-related lower extremity amputations. Diabetes Care 2001; 24: 1799-1804.

16- Breakey JW: Body image: The lower-limb amputation. J Prosthetics Orthotics 1997; 9: 58-62. 